\title{
横过西昆仑造山带与塔里木盆地结合带的 深地震反射剖面
}

高 锐 ${ }^{(1)}$ 黄东定 ${ }^{(2)}$ 卢德源 ${ }^{(1)}$ 钱桂华 ${ }^{2}$ 李英康 ${ }^{(1)}$ 匡朝阳 ${ }^{(2)}$ 李秋生 ${ }^{(1)}$ 李朋武 (1) 冯如进 ${ }^{(2)}$ 管 烨(1)

(1)中国地质科学院地质研究所岩石圈研究中心, 北京 100037; (2)中国新星石油公司第六物探大队, 南京 210009. Email: gaorui@cags.cn.net)

摘要 横过西昆仑造山带与塔里木盆地结合地带的深地震反射剖面, 揭示出青藏高原西北缘山盆结合地带地壳与上地幔顶部的精细结构, 发现了青藏高原西北缘岩石圈向北俯冲, 并与向南俯 冲的塔里木岩石圈在西昆仑山下相碰撞的证据. 这种大陆岩石圈相向俯冲碰撞图像, 确定了西昆 仑山与塔里木盆地在岩石圈尺度的耦合关系, 反映出陆内大陆-大陆的碰撞过程.

关键词 青藏高原 西昆仑造山带 塔里木盆地 深地震反射 相向俯冲碰撞 山-盆耦合

大陆内部的陆-陆碰撞过程是大陆动力学的核心问题. 青藏高原被视为印度与欧亚两个大 陆板块于新生代碰撞的结果, 是典型的陆-陆碰撞地带. 多年来, 人们一直在青藏高原南部追 踪印度板块与欧亚板块的碰撞过程, 探讨高原隆升的动力学机制 ${ }^{[1 \sim 5]}$.

近年来, 通过岩石地球化学和地球物理研究, 发现了塔里木-阿拉善大陆地块向青藏高原 北部俯冲碰撞的一些线索 ${ }^{\left[{ }^{[09}\right.}$. 青藏高原北部可能也正在发生陆-陆碰撞作用 ${ }^{[10 \sim 13]}$, 只不过发 生在这里的陆-陆碰撞过程还鲜为人知. 显然, 探测和揭示青藏高原北部的陆-陆碰撞过程, 对 于探索高原隆升机制是十分重要的, 其结果将改变印度板块与欧亚板块仅在高原南部相互碰 撞的传统认识.

西昆仑造山带位于青藏高原的西北边缘, 向北面对塔里木盆地, 是探测和揭示青藏高原 北部的陆-陆碰撞过程的理想地区. 为了揭示西昆仑造山带与塔里木盆地结合地带地壳与上地 幔顶部的精细结构, 追踪塔里木盆地岩石圈俯冲到西昆仑造山带之下的证据、碰撞过程和规模, 于 1998 年夏季, 横过盆-山结合部位实施了深地震反射剖面探测.

\section{1 深地震反射剖面位置与构造背景}

深地震反射调查剖面(以下简称: 剖面)北起塔里木盆地南缘的策勒县北 $10 \mathrm{~km}$ 处 $\left(37^{\circ} 05^{\prime} \mathrm{N}\right.$, $80^{\circ} 48^{\prime} \mathrm{E}$ ), 海拔高程约 $1300 \mathrm{~m}$, 沿策勒至恰哈公路近南北向展布, 剖面南端止于西昆仑山北 部的其满喀肉克 $\left(36^{\circ} 14^{\prime} \mathrm{N}, 80^{\circ} 32^{\prime} \mathrm{E}\right)$, 海拔高程约 $2900 \mathrm{~m}$, 剖面全长 $102 \mathrm{~km}$. 另在恰哈至 铁克理克塔格布置了 $11 \mathrm{~km}$ 长的东西向横剖面, 以追踪地壳结构的横向变化(图 1).

剖面地表被第四系覆盖. 剖面北部穿过叶城-和田地震活动带, 该地震带呈北西走向展布 于塔里木盆地西南缘, 断裂性质以走滑为主, 震源深度达 45 (和田) $74 \mathrm{~km}$ (叶城) ${ }^{[15]}$. 剖面中 部(恰哈附近)西临铁克理克隆起, 剖面南部接近库地缝合带.

大致以库地蛇绿岩带为界, 西昆仑造山带可分为南北两个基底构造带 ${ }^{[14]}$. 北带基底主要 由长城系及更老的变质地层组成, 根据区域地质调查研究, 这套地层应是塔里木盆地的一部 分. 南带基底是一套变质深浅不一、构造变形复杂的变质岩系, 与北带有显著的差别, 年代较 新(主体为晚元古代 早寒武世), 结晶程度低, 活动性大. 西昆仑造山带南北两种不同类型和 


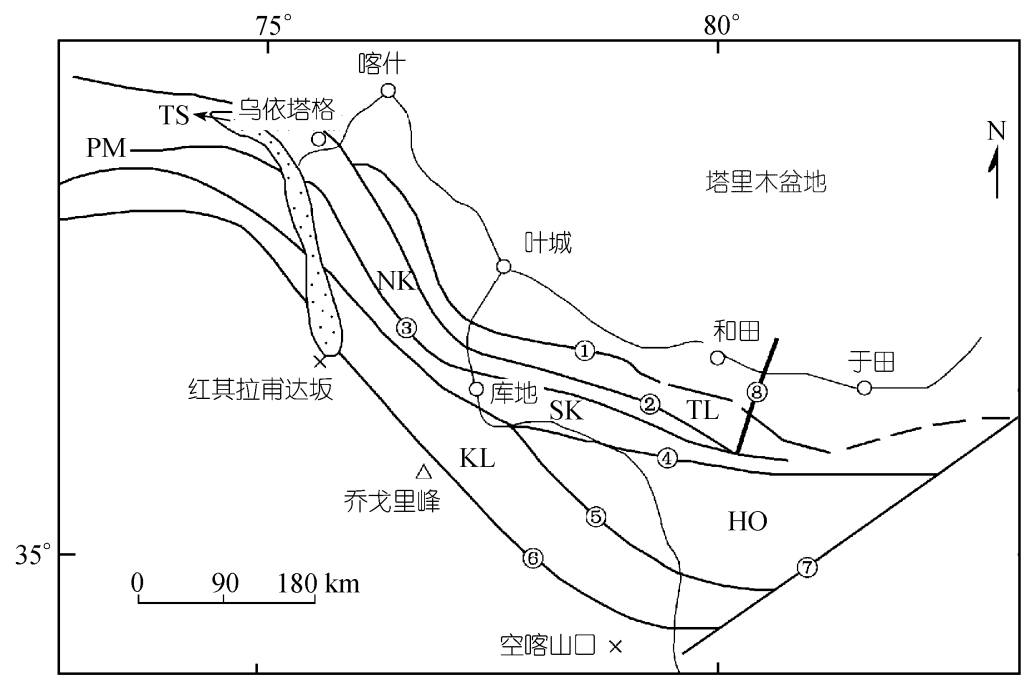

图 1 深地震反射剖面位置示意图

构造背景据文献[14]. PM: 帕米尔高原; TS: 塔什库尔干断陷; TL: 铁克里克隆起; NK: 北昆仑构造带; SK: 南昆仑构造带; KL: 喀喇昆仑构造带; HO: 可可西里-芫塘地

体. (1)西昆仑山前断裂; (2) 昆仑北部断裂; (3)昆仑中央断裂; (4)昆仑南缘 (康 西瓦)断裂; (5)泉水沟断裂; (6)喀喇昆仑断裂; (7)阿尔金断裂, (8)示剖面位置

时代的变质基底, 也曾被称为昆北型硬基底, 昆南型软基底 ${ }^{[16]}$. 库地蛇绿岩带可能代表消失 了的洋盆的残余, 潘裕生 ${ }^{[17]}$ 称其为原特提斯洋, 闭合于加里东运动, 形成库地缝合带(潘称其 为青藏高原第五缝合带). 西昆仑造山带南侧的康西瓦断裂在库地以西是西昆仑与喀喇昆仑的 分界线, 在库地以东是与羌塘-可可西里地体的分界线.

\section{2 反射地震数据采集和处理}

采用爆破震源. 施工工区地震地质条件复杂, 剖面南部为深切河谷, 北部为戈壁滩. 以井 中爆破和河岸陡坡深坑爆破相结合方式激发地震波. 深坑一般自地表深达 $30 \sim 50 \mathrm{~m}$, 部分达 80 90 m. 井中爆破一般为多井组合, 单井井深 $20 \sim 30 \mathrm{~m}$. 小炮药量 $48 \sim 72 \mathrm{~kg}$, 炮间距 $500 \mathrm{~m}$; 每隔 $5 \mathrm{~km}$ 放 $200 \mathrm{~kg}$ 药量大炮. 单边放炮. 使用法国产 SN 388 多道 24 位地震仪, 300 道(后扩 展为 432 道)接收, 道间距 $50 \mathrm{~m}$, 平均叠加 15 次, 检波器主频 $12 \mathrm{~Hz}$, 记录长度 $30 \mathrm{~s}$.

使用 Micro Max 和 Pro Max 两套地震数据处理系统, 对采集的数据实行现场监控, 现场 绘制单炮记录图, 监视采集信号的信噪比, 并对当日采集的地震数据进行初步处理, 绘出初叠 剖面, 及时指导第 2 天的采集工作，有效地保证了数据采集工作的质量.

使用 Pro Max 系统进行数据处理. 进行了叠加面元参数选择、高程校正、真振幅恢复、 频谱分析及滤波参数测试等多项叠前数据净化处理. 对叠加方法、叠后去噪处理及偏移技术 方 法和参数进行了认真测试和选择, 特别加强了其中的仿阵列滤波和振幅处理技术. 经精细 处理, 获得 $0 \sim 30 \mathrm{~s}$ 的叠加与偏移时间剖面, 获得多套反射波组信息. 清晰的莫霍面(Moho)反 射震相(图 2)表明此剖面的采集与处理是成功的, 为研究西昆仑造山带-塔里木盆地的结晶基 底、壳内结构、莫霍面乃至地幔顶部状态和山-盆耦合作用提供了基础资料和科学依据. 


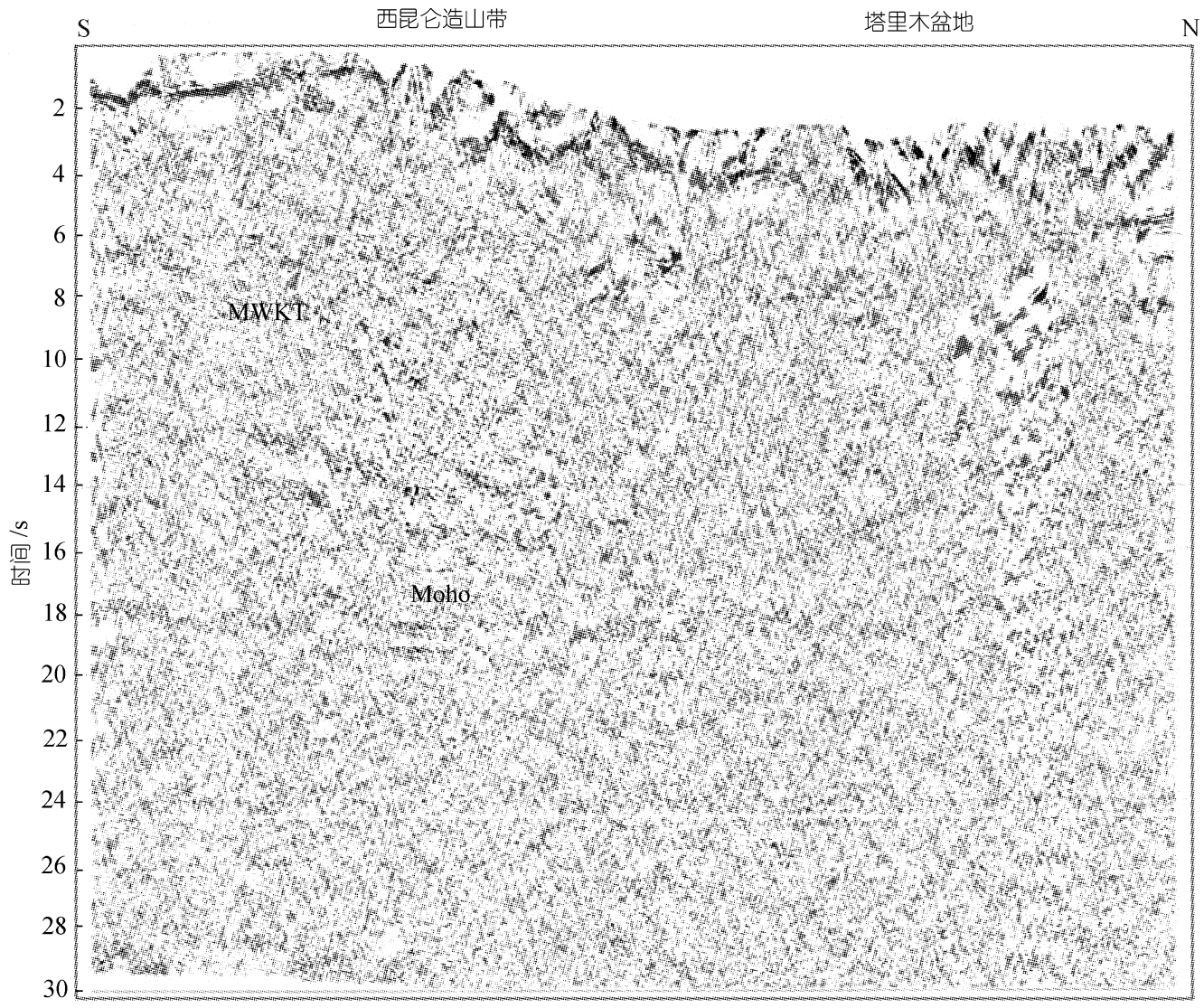

图 2 深地震反射叠加剖面(未偏移)

\section{3 深地震反射剖面的基本特征}

以大尺度比例尺绘制的深地震反射时间剖面揭示出西昆仑山北缘和塔里木盆地南缘地壳 及上地幔顶部细结构的反射波图像 (见封面图和图 2). 由浅至深揭示出 4 大套反射层系: $0 \sim 6 \mathrm{~s}$ (双程走时, 下同) 之间出现多套高角度雉形或羽状形反射波组, 表明了该区浅层构造的复杂 性, 其中 3 5 s 之间发育 1套多相位、强反射似层状地震相, 自南而北可对比, 推测为该区 结晶基底, 南浅北深; 7 8s 之间出现 1 组多相位、中反射强度丘状 似层状地震相, 由南向 北可连续追踪, 反映出该区上地壳底界面的结构特征; 8 18 s 之间, 剖面南段出现 6 7 组北 倾、可连续追踪、由浅至深倾角逐渐变小的中 强反射地震相, 反映出西昆仑下地壳由南向北倾 斜的结构特征. 剖面北段出现 3 4 组南倾反射波, 表现出塔里木岩石圈向西昆仑山下插入的 反射结构图像; 18 19 s 左右出现 1套密集多相位、可断续追踪的中等反射强度似层状地震 相、北段略有抬升的反射波组, 表现出西昆仑- 塔里木莫霍面以平的反射为主要的反射特征. 在 COCORP 的反射剖面中, 平的 Moho 反射通常被解释为是新形成的 ${ }^{[18]}$. 西昆仑造山带与塔 里木盆地碰撞带下平缓的 Moho 反射, 可能也代表了碰撞后新形成的 Moho. 按下地壳平均 P 波速度为 $6.30 \mathrm{~km} / \mathrm{s}$ 计算, 则 Moho 深度在 $57 \sim 60 \mathrm{~km}^{[19]} ; 19 \sim 30 \mathrm{~s}$ 之间隐约发育多套大角度北 
倾和少量南倾反射波组, 同时穿插出现多套中等强度似层状地震相, 反映出地幔盖层的地震 反射特征. 深地震反射剖面的这些反射波组特征, 清晰地反映出剖面沿线岩石圈结构的空间 变化.

\section{4 构造意义}

地震剖面上最显著的特征是西昆仑山下向北倾斜与塔里木盆地南缘下向南倾斜的多组强 反射. 它们构成了塔里木岩石圈与青藏高原西北缘岩石圈在西昆仑山下相向倾斜碰撞的地震 证据.

石油地震反射剖面曾显示出西昆仑山北带的铁克理克隆起向北逆冲在塔里木盆地南缘之 上, 塔里木盆地基底向西昆仑山下弯曲, 暗示了塔里木盆地向青藏高原下俯冲的可能性 ${ }^{[20]}$. 震源机制研究支持塔里木盆地向西昆仑山之下插入 ${ }^{[7]}$. 在西昆仑山上发现的新生代晚期高钾 火山岩, 被推测为塔里木盆地俯冲到西昆仑山之下, 岩石圈发生拆沉引发地幔活动的结果 ${ }^{[6]}$. 新的热年代学数据和山前磨拉石研究, 说明西昆仑山作为青藏高原西北边界山脉, 自 $5 \mathrm{Ma}$ 以 来发生了脉动式由缓慢到快速的隆升过程 ${ }^{[14]}$.

深地震反射剖面不仅在更大的岩石圈尺度上揭露出塔里木盆地向青藏高原西北缘下俯冲 的空间行为, 而且描绘出作为现今亚洲板块的前缘即刚性的塔里木岩石圈与青藏高原岩石圈 相碰撞的几何图像. 同时, 这种南北相向倾斜的反射结构图像揭示出西昆仑山与塔里木盆地 在岩石圈尺度呈 “ $\mathrm{V}$ ” 型山-盆耦合关系, 这种 “V” 型的耦合型式可能是陆内大陆-大陆碰撞 过程的一种表现方式.

特别应指出的是, 西昆仑山下北倾的反射是出人预料的. 它与塔里木南倾的反射构成的 双向相向俯冲碰撞的构造型式, 在青藏高原岩石圈下部未经发现过. 与深地震反射剖面位置 重合进行的宽频地震研究, 随后也得到类似的结果, 佐证了反射剖面的发现, 并表明北倾的反 射向下可延伸到 $180 \mathrm{~km}^{1}$. 对比邻区揭示印度大陆俯冲到藏南之下的深地震反射剖面 ${ }^{[21}$ 和表 征雅鲁藏布江缝合带下特提斯洋壳俯冲残余体的反射图像 ${ }^{[22]}$, 可认为昆仑山下北倾的反射是 大陆岩石圈俯冲作用形成的. 这套北倾的反射由多组强反射组成, 上陡下缓, 最上一组反射振 幅最强, 在纵横近似 $1: 1$ 的显示剖面上, 用地壳平均速度为 $6.0 \mathrm{~km} / \mathrm{s}$ 统一把地震波走时换算 成深度, 并把反射剖面投影到南北走向上, 得出最上一组北倾反射的倾角为 $35^{\circ}$, 自剖面南端 $25 \mathrm{~km}$ 深处向北倾斜, 明显延伸到塔里木的岩石圈地幔中. 它是逆冲断裂的反映, 在此将其命 名为西昆仑主逆冲断裂(简写为 MWKT: Main West Kunlun Thrust), 一个大陆岩石圈正沿此逆 冲断裂向北俯冲. 尽管我们尚不能确定这一大陆岩石圈是来自印度板块的, 还是欧亚板块的. 但如果是前者, 则深反射剖面就捕捉到印度大陆与欧亚大陆现今碰撞交锋的前缘图像, 如图 3(a)所示. 对照地表构造的划分, 如果顺 MWKT 的倾向沿南北方向向南向上延伸投影, 则北 倾的反射对应着可可西里-姜塘地体, 如图 3(b)所示. 然而, 北倾的反射向南延伸是否会变平, 一直延伸连接到喀喇昆仑山下的印度板块, 就像推测 MHT 向南变平延伸到喜马拉雅山前一 样? 这需要布置新的探测剖面加以证实. 

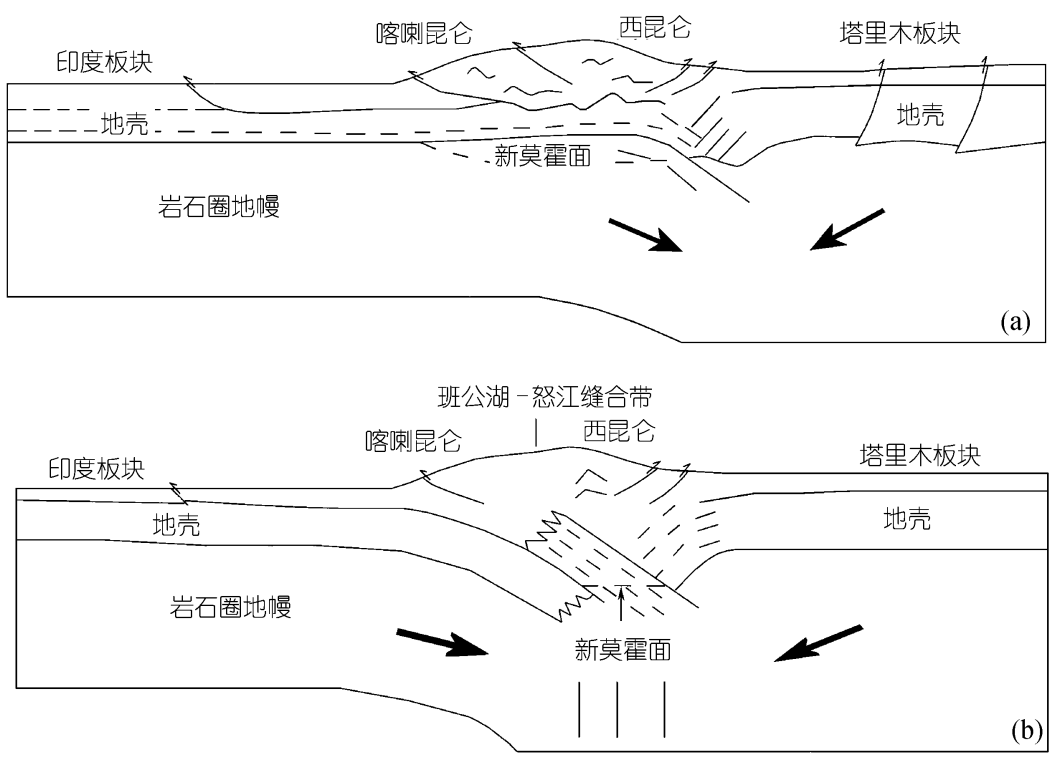

图 3 深地震反射剖面的构造解释

致谢 感谢与李廷栋、肖序常、丁国渝和陈运泰院士, 于占元高级工程师、赵文津研究员、袁学诚高 级工程师、刘训研究员、K. D. Nelson 教授、尹安教授、金小赤和李德贵研究员、高弘副研究员、姚瑞 均博士等的讨论. 本工作为国土资源部(9501204)、国家自然科学基金(批准号: 49734230)、国家“305”专 项(96-915-07-03)和国家重点基础研究发展规划（G1998040800)资助项目.

\section{参考文献}

1 Argand E. La tectonique de I' Asic. Int Geol Congr Rep Sess, 1924, 13: $170 \sim 372$

2 Dewey J F, Burke K. Tibetan, Variscan and Precambrian basement reactivation: Products of continental collision. J Geol, 1973, 81: $683 \sim 692$

3 Ni J, Barazangi M. Seismotectonics of the Himalayan collision zone: Geometry of the underthrusting Indian plate beneath Himalaya. J Geophys Res, 1984, 89: $1147 \sim 1163$

4 Molnar P. The Geological evolution of the Tibetan plateau. American Scientist, 1989, 77: $350 \sim 360$

5 Li T D. The process and mechanism of the rise of the Qinghai-Tibet plateau. Tectonophysics, 1996, 260: 45 53

6 Arnaud N, Vidal Ph O, Tapponnier P, et al. The high $\mathrm{K}_{2} \mathrm{O}$ volcanism of the western Tibet: Geochemistry and tectonic implications. Earth and Planetary Science Letters, 1992, 111: $351 \sim 367$

7 汪素云, 时振梁, 环文林. 1980 年 2 月 14 日新疆叶城地震———次破坏性的中源地震. 地震学报, 1992, 14(2): 137 143

8 高 锐, 成湘州, 丁 谦. 格尔木-额济纳旗地学断面地球动力学模型初探. 地球物理学报, 1995, 38(增刊 II ): $3 \sim 14$

9 Wittlinger G, Tapponnier P, Poupinet G, et al. Topographic evidence for localized lithospheric shear along the Altyn Tagh Fault. Science, 1998, 28: $74 \sim 76$

10 Willett S D, Beaumont C. Subduction of Asian lithosphere mantle beneath Tibet inferred from models of continental collision. Nature, 1993, 369: $642 \sim 645$

11 曾融生, 丁志峰, 吴庆举. 喜马拉雅-祁连山地壳构造与大陆-大陆碰撞过程. 地球物理学报, 1998, 41(1): 49 60

12 高 锐, 李廷栋, 吴功建. 青藏高原岩石圈演化与地球动力学过程. 地质论评, 1998, 44 (4): $389 \sim 395$

13 Gao R, Cheng X Z, Wu G J. Lithospheric structure and geodynamic model of the Golmud-Ejin transect in northern Tibet. Geological Society of America, 1999, Special Paper 328: 9 17 
力学研究发展. 北京: 地震出版社, 1999. 105 113

15 高国英, 王盛泽. 天山中强震震源机制解. 内陆地震, 1997, 11(增刊): $148 \sim 158$

16 姜春发, 杨经绥, 冯秉贵, 等. 昆仑开合构造, 北京: 地质出版社, 1992. 1 224

17 潘裕生. 青藏高原第五缝合带的发现与论证. 地球物理学报, 1994, 37(2): 184 192

18 Brown L, Wille D, Zheng L. et al. COCORP: New perspectives on the deep crust. Geophys J R Asir Soc, 1987, 89: 47 54

19 Gao R, Li D X, Lu D Y, et al. Deep seismic reflection profile across contact zone of West Kunlun and Tarim along the Xinjiang geotransect in NW China. Terra Nostra, Schriften der Alfred-Wegener-Stiftung, 1999, 2: $49 \sim 50$

20 Li D. Hydrocarbon occurrences in the petroliferous basins of western China. Mar Pet Geol, 1995, 12: $26 \sim 34$

21 Zhao W, Nelson K D, INDEPTH Team. Deep seismic reflection evidence for continental underthrusting beneath Tibet. Nature, 1993, 366: $557 \sim 559$

22 Mayakovsky Y, Klemperer S L, Ratschbacher L, et al. Midcrustal reflector on INDEPTH wide-angle profiling: An ophiolitic slab beneath the India-Asia suture in southen Tibet ? Tectonics, 1999, 18(5): $793 \sim 808$

(2000-02-29 收稿, 2000-05-25 收修改稿) 